\title{
Functional Status Geriatric Scores: Single-Handed Tools for 30-Day Mortality Risk After Hip Fracture
}

\author{
Carmen da Casa $\mathbb{D}^{\prime}$ \\ Carmen Pablos-Hernández ${ }^{1,2}$ \\ Alfonso González-Ramírez ${ }^{1,2}$ \\ Juan F Blanco $\mathbb{I D}^{1,3}$ \\ 'Instituto de investigación biomédica de \\ Salamanca (IBSAL), Salamanca, Spain; \\ ${ }^{2}$ Othogeriatric Unit, Hospital \\ Universitario de Salamanca, Salamanca, \\ Spain; ${ }^{3}$ Trauma and Orthopedic Surgery \\ Department, Hospital Universitario de \\ Salamanca, Salamanca, Spain
}

Correspondence: Juan F Blanco

Trauma and Orthopedic Surgery

Department, Hospital Universitario de

Salamanca, Paseo San Vicente, 58-182,

Salamanca, 37007, Spain

Tel +3492329II00 ext. 55390

Email jfblanco@usal.es
Background: The 30-day mortality rate after hip fracture surgery has been considered as an indirect indicator of the quality of care. This work aims to appraise the Barthel Index, Katz Index, Lawton-Brody Index, and Physical Red Cross Scale registered in the Comprehensive Geriatric Assessment at admission on the of 30-day death probability after hip fracture surgery.

Methods: Prospective study including 899 hip fracture patients over 65. Bed-ridden, nonsurgically treated patients, and high energy trauma or tumoral etiology fractures were excluded. Variables distribution were assessed by $\chi^{2}$, U-Mann Whitney and we performed binary logistic regression and equal tailed Jeffreys 95\% CI for risk assessment. $\mathrm{P}<0.05$ was considered statistically significant.

Results: We noted a 30-day mortality rate of $5.9 \%$. We related Barthel Index $(\mathrm{OR}=0.986$ [0.975-0.996], p=0.010), Katz Index (OR=1.254 [1.089-1.444], p=0.002), Lawton-Brody Index $(\mathrm{OR}=0.885$ [0.788-0.992], $\mathrm{p}=0.037)$, and Physical Red Cross Scale $(\mathrm{OR}=1.483$ [1.094-2.011], $\mathrm{p}=0.011$ ) with the 30-day mortality of patients after hip fracture surgery. We also validated the Barthel Index inflection point $(0-55)\left(\mathrm{OR}_{\mathrm{BI}(0-55)}=2.428\right.$ [1.379-4.275], $\mathrm{p}=0.002)$ and Katz Index inflection point $(\mathrm{A}-\mathrm{B})\left(\mathrm{OR} \mathrm{KI}_{(\mathrm{A}-\mathrm{B})}=0.493[0.273-0.891], \mathrm{p}=0.019\right)$ for the assessment of the highest risked patients.

Conclusion: The geriatric functional status scores would be useful multifunctional and standalone tools in the assessment of hip fracture patients as singly predictors of 30-day mortality.

Keywords: comprehensive geriatric assessment, hip fracture, mortality, geriatric scores

\section{Background}

One of the most interesting topics in older hip fracture management is to identify indicators to foresee the patients' outcome. These indicators would allow clinicians to establish preventive measures and allocate resources for those patients with a higher risk of mortality.

Older hip fracture patients' treatment requires a multidisciplinary approach carried out in the so-called Orthogeriatric Units. The Comprehensive Geriatric Assessment (CGA) is a key tool throughout the admission process, that reports on the patient's functional status and has been related to the hip fracture outcome. ${ }^{1}$ The CGA includes, among other clinical, nutritional, and social assessments, the evaluation of some geriatric functional status scores and geriatric syndromes. ${ }^{2,3}$ Barthel Index (BI), Katz Index (KI), and Lawton-Brody Index (LBI) functional status scores are broadly used in a standardized way as part of the CGA. The Physical Red Cross Scale (PCRS) is also a mobility score widely used in Spain. 
These geriatric scores, along with the clinical information, elucidate the functional situation of the patient. The deeper insight would contribute for the in-hospital monitoring and later follow-up.

Diverse tools lay out to predict the outcome of hip fracture patients' surgically treated, such as the NHFS (Nottingham Hip Fracture Score), AHFS (Almelo Hip Fracture Score), or O-Possum. ${ }^{4,5}$ However, the variability along the world population and health-care models, could compromise its application due to the availability of certain resources. Some geriatric scores have been also previously pointed as predictors of in-hospital mortality for patients undergoing surgery. ${ }^{6}$ Our working group demonstrated the usefulness of geriatric scores as predictors of long-term mortality risk in a shorter cohort, ${ }^{7}$ by establishing geriatric score inflection points from which the risk of long-term survival was significantly decreased.

The aim of this work is to appraise the influence of baseline BI, KI, LBI, and PRCS on the 30-day mortality risk of older hip fracture patients. We also aim to evaluate the possible usefulness of the geriatric scores inflection points previously defined on BI, KI, and LBI on the 30 day mortality rate in older hip fracture patients.

\section{Methods}

\section{Design and Population}

We designed a prospective observational study, including all hip fracture patients aged 65 and older admitted from January 1, 2018 to December 31, 2019 to the Orthogeriatric Unit of the University Hospital of Salamanca (UHS). All patients included in the study expressed their consent to participate by signed consent. Bed-ridden patients $(\mathrm{PRCS}=5)$, high energy trauma or tumoral etiology fractures and those cases that were not surgically treated were excluded.

Overall, a complete CGA was performed in 919 patients during the study period. We follow-up patients for 30-day mortality, asserting an attrition rate of $2.2 \%$. A total of 899 patients were included in the study.

\section{Demographic and Clinical Variables}

Sociodemographic variables such as gender, date of birth and admission, and place of residence were collected upon admission. We also recorded the type of fracture, the type of surgical procedure, and destination at discharge.

\section{Geriatric Scores}

At the UHS Orthogeriatric Unit, the following geriatric scores are used as part of CGA: Barthel Index, Katz Index, Lawton-Brody Index, and Physical Red Cross Scale.

The $\mathrm{BI}^{8}$ collects data on the degree of capability for the development of 10 basic activities of daily living (ADL). For each activity analyzed, a gradual score is applied in 5 points, according to the patient's ability to perform it. BI punctuations go from 0 to 100 . On $\mathrm{BI}$, the higher score relate the better functional status.

The $\mathrm{KI}^{9}$ estimates the independence of the patient to perform basic ADL. It analyses 6 functions from which categorization of patients originates possible situations ranging from the total independence, named with the letter A, to the total dependence, indicated with the letter $\mathrm{G}$.

The $\mathrm{LBI}^{10}$ evaluates instrumental activities of daily living (IADL). The LBI assigns a score from 0 to 8 ; the highest score indicates the best functional capability. Due to the characteristics of the IADL analyzed, LBI has been traditionally applied differentiating the gender of the patient and limiting to 4 the maximum score for men. ${ }^{11}$ At UHS, the whole questionnaire was determined regardless of patient gender.

For these three geriatric scores, we have previously described an inflection point from which the survival rate of patients after hip fracture surgery would be significantly abridged. ${ }^{7}$

The Physical Red Cross Scale ${ }^{12}$ evaluates the physical ambulatory ability of the patient, similarly to the Functional Ambulation Classification (FAC). The physical-status evaluation of PRCS is concerning 5 levels of ambulatory ability from 0 , which indicates full capability, to 5, which indicates no ambulatory capability. This score was also used as an exclusion variable in our study for bed-ridden patients $(\mathrm{PCRS}=5)$.

\section{Statistical Analysis}

Data were imported into a database for statistical analysis with the $\operatorname{IBM}^{\circledR} \operatorname{SPSS}^{\circledR}$ Statistics program (v.26). Descriptive statistics included mean, standard deviation, and median and interquartile range. Sample distribution was addressed by Kolmogorov-Smirnoff test with Lilliefors correction and Q-Q plots. We ascertain the statistically significant differences among groups by $\chi^{2}$ and U-Mann-Whitney tests. Confidence intervals for reported probabilities were calculated by equal tailed Jeffreys prior intervals. The Odds Ratios (OR) were estimated by binary 
logistic regression. In all cases, a p-value of less than 0.05 was considered statistically significant.

\section{Results}

The study population was composed of 899 hip fracture patients over 65 . One in four patients were men $(26.7 \%)$ and the mean age was 86.3 years old.

Non-rural patients represented $51.6 \%$ of participants (residents from municipalities with more than 12,500 inhabitants), and $32.0 \%$ of participants came from a nursing home. A total of 472 patients were institutionalized at a nursing home after hospital discharge $-32.8 \%$ of noninstitutionalized patients at admission were institutionalized at discharge - . A social worker was involved in $17.6 \%$ of cases. Incidence by type of hip fracture was also studied, showing that most cases it was a trochanteric fracture, whose surgical intervention treatment was osteosynthesis-based. Table 1 shows the distributions of the detailed biodemographic and fracture-related features of patients according to their 30-day survival or dead status.

The mean time to surgery (TTS) was $2.94 \pm 2.55$ days, noting $34.1 \%$ of patients operated within the first $48 \mathrm{~h}$, and
$17.7 \%$ of patients operated within the first $24 \mathrm{~h}$. We noted a 30 -day mortality rate of $5.9 \%$.

Regarding the patients' functional status measured by the BI, KI, LBI, and PCRS geriatric scores, Figure 1 shows the population distribution along the geriatric scores categories on shadow area charts, and the30-day death probability with 95\% confidence intervals. The complete death probability values addressed are available on Supplementary Table 1.

\section{Barthel Index}

The mean punctuation in BI of our population was 72.8 \pm 23.4 . We noted significant decreasing BI on aging groups $(\mathrm{p}<0.001)$, and lower BI punctuation on women $(\mathrm{p}=0.013)$ and institutionalized patients at admission $(\mathrm{p}<0.001)$. However, no differences on BI were achieved for new institutionalized patients at discharge $(\mathrm{p}>0.05)$, neither regarding the waiting time to surgery of patients (TTS $<24 \mathrm{~h}, \mathrm{p}>0.05$; TTS $<48 \mathrm{~h}, \mathrm{p}>0.05$ ).

BI was significantly related to 30-day mortality (OR per point $=0.986[0.975-0.996], p=0.010)$, despite the gender or age of patients (Supplementary Table 2) The distributions of

Table I Biodemographic and Fracture-Related Features of Patients

\begin{tabular}{|c|c|c|c|c|c|c|c|}
\hline \multicolumn{4}{|c|}{ Biodemographic Features } & \multicolumn{4}{|c|}{ Fracture-Related Features } \\
\hline & Survival & 30-Day Mortality & \multirow[t]{2}{*}{ p-value } & & Survival & 30-Day Mortality & \multirow[t]{2}{*}{ p-value } \\
\hline & $(n=846)$ & $(n=53)$ & & & $(n=846)$ & $(n=53)$ & \\
\hline \multicolumn{3}{|l|}{ Gender } & 0.012 & \multicolumn{3}{|l|}{ Side of fracture } & 0.727 \\
\hline Female & $74.2 \%$ & $58.5 \%$ & & Right & $47.8 \%$ & $52.2 \%$ & \\
\hline \multicolumn{3}{|l|}{ Age } & 0.009 & Left & $45.3 \%$ & $54.7 \%$ & \\
\hline $\begin{array}{l}\text { Mean } \pm \text { SD } \\
\text { Median[IQR }]\end{array}$ & $\begin{array}{l}86.1 \pm 6.7 \\
87[82,91]\end{array}$ & $\begin{array}{l}88.9 \pm 6.5 \\
89[84.5,93]\end{array}$ & & \multicolumn{3}{|l|}{ Type of fracture } & 0.628 \\
\hline Grouped age & & & 0.036 & Intracapsular & $41.0 \%$ & $47.2 \%$ & \\
\hline $65-79$ years-old & $16.7 \%$ & $7.5 \%$ & & Basicervical & $4.6 \%$ & $3.8 \%$ & \\
\hline $80-89$ years-old & $51.7 \%$ & $45.3 \%$ & & Trochanteric & $44.2 \%$ & $41.5 \%$ & \\
\hline$>90$ years-old & $31.7 \%$ & $47.2 \%$ & & Subtrochanteric & $6.3 \%$ & $1.9 \%$ & \\
\hline \multicolumn{3}{|c|}{ Residence (municipality) } & 0.302 & Periprosthetic & $3.9 \%$ & $5.7 \%$ & \\
\hline Rural & $48.8 \%$ & $41.5 \%$ & & \multicolumn{3}{|l|}{ Surgical procedure } & 0.408 \\
\hline \multicolumn{3}{|c|}{ Institution-living (nursing home) } & & Osteosynthesis & $57.4 \%$ & $54.7 \%$ & \\
\hline At admission & $32 . \%$ & $30.2 \%$ & 0.766 & Hemiarthroplasty & $40.0 \%$ & $45.3 \%$ & \\
\hline At discharge* & $54.2 \%$ & $66.7 \%$ & 0.225 & Total hip arthroplasty & $2.6 \%$ & $0 \%$ & \\
\hline
\end{tabular}

Note: *In-hospital exitus are excluded from the analysis.

Abbreviations: SD, standard deviation; IQR, interquartile range. 

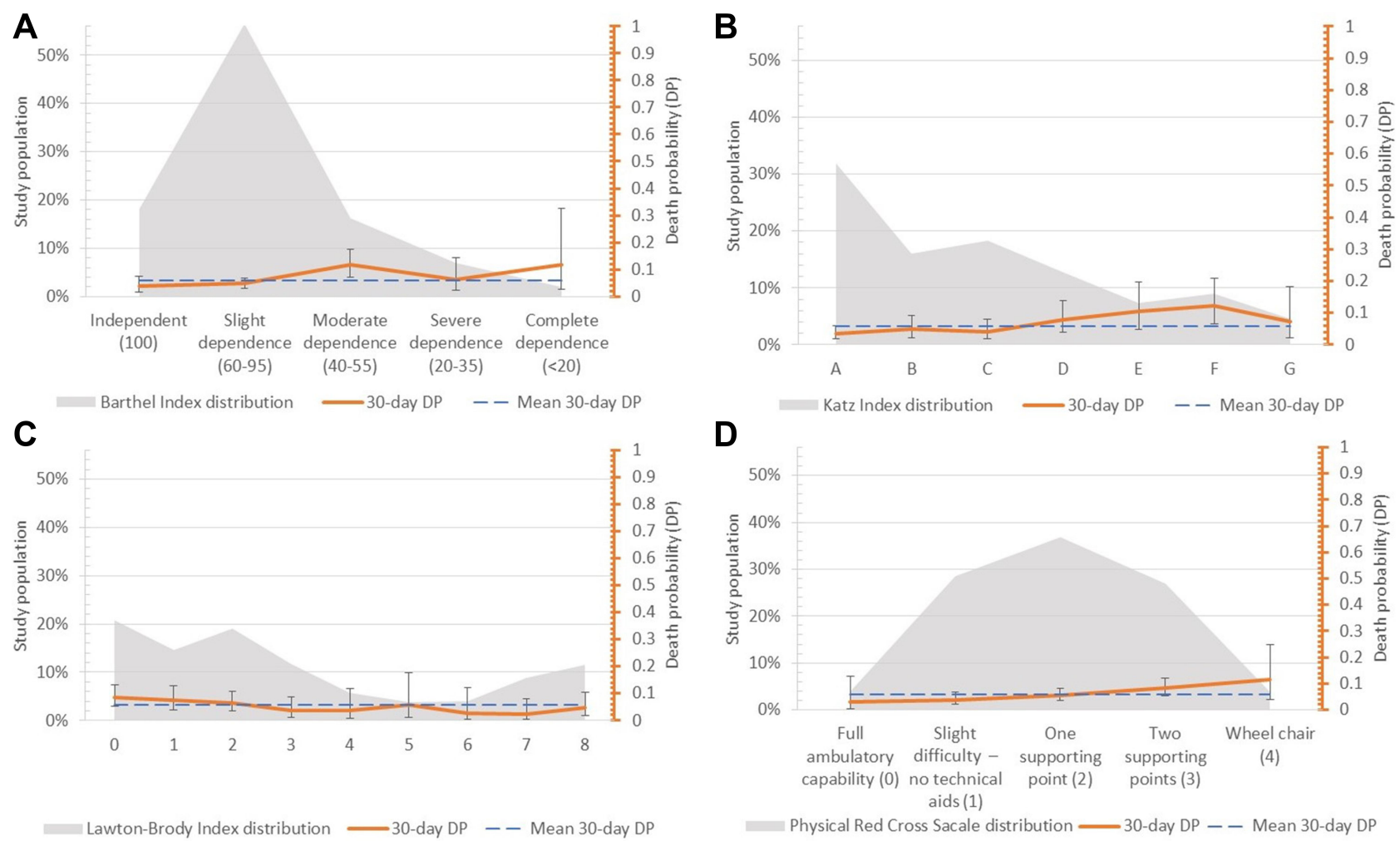

Figure I Distribution of the study population represented in an area chart over the different categories of the geriatric scores analyzed: Barthel Index (A), Katz Index (B), Lawton-Brody Index (C), and Physical Red Cross Scale (D). The orange line on the left axis represents the probability of death at 30 days with $95 \%$ confidence intervals. The discontinuous blue line marks the mean 30-day mortality rate.

BI punctuation regarding the 30-day mortality status of patients are shown in Table 2 and represented in Figure 2A.

The cut-off for the inflection point previously determined for BI (BIIP) was set at 60 points, grouping patients presenting moderate and severe dependence (BI 0-55) and patients showing slight dependence or total independence (BI 60-100). Analyzing the study population by the distribution of BIIP, we observed no differences regarding the gender of patients, new institutionalized patients at discharge or time to surgery ( $p>0.05$, in all cases), but we did with institutionalized patients at admission $(\mathrm{p}<0.001)$ and the more aging patients $(\mathrm{p}<0.001)$. We noted a significantly increased risk for early mortality at this point, noting that moderate or severe dependent patients had double increased risk $\left(\mathrm{OR}_{\mathrm{BI}(0-55)}=2.428\right.$ [1.379-4.275], $\left.\mathrm{p}=0.002\right)$.

\section{Katz Index}

The most frequent category of $\mathrm{KI}$ in our population was A $(31.9 \%)$. We noted significant decreasing $\mathrm{KI}$ on aging groups $(\mathrm{p}<0.001)$ and on institutionalized patients at admission $(p<0.001)$, but no differences in KI were achieved regarding new institutionalized patients at discharge, the gender of patients, or the early surgery rates (TTS $<24 \mathrm{~h} / 48 \mathrm{~h}, \mathrm{p}>0.05$, in all cases).

$\mathrm{KI}$ was significantly related to 30 -day mortality (OR per point $=1.254$ [1.089-1.444], $\mathrm{p}=0.002$ ), despite the gender or age of patients (Supplementary Table 2). The distributions of KI punctuation regarding the 30-day mortality status of patients are shown in Table 2 and represented in Figure 2B.

The inflection point previously determined for $\mathrm{KI}$ (KIIP) was set at B category, grouping patients displaying high independence (KI A-B) and patients showing any dependency (KI C-G). Analyzing the study population by the distribution of KIIP, we observe no differences regarding the gender of patients or new institutionalized patients at discharge $(\mathrm{p}>0.05)$, but we noted a lower independent patient (KI A-B) rate on the institutionalized population at admission $(p<0.001)$ and aging patients $(p<0.001)$. We noted a greater proportion of independent patients operated within the first $48 \mathrm{~h} \quad(\mathrm{p}=0.018)$. We noted a significantly decreased risk for early mortality at this point $\left(\mathrm{OR}_{\mathrm{KI}(\mathrm{A}-\mathrm{B})}=0.493[0.273-0.891], \mathrm{p}=0.019\right)$. 
Table 2 Barthel Index and Katz Index Distribution Along the Study Population

\begin{tabular}{|c|c|c|c|c|}
\hline & \multirow{2}{*}{$(n=846)$} & \multirow{2}{*}{$\begin{array}{c}\begin{array}{c}30-\text { Day } \\
\text { Mortality }\end{array} \\
(n=53)\end{array}$} & \multirow[t]{2}{*}{ p-value } \\
\hline & & & & \\
\hline Barthel & Mean \pm SD & $73.32 \pm 23.34$ & $64.62 \pm 23.82$ & 0.008 \\
\hline Index & Median [IQR] & $75[60,95]$ & $70[45,80]$ & \\
\hline \multicolumn{2}{|c|}{ Grouped BI } & & & 0.014 \\
\hline \multicolumn{2}{|c|}{ Independent (100) } & $18.7 \%$ & $11.3 \%$ & \\
\hline \multicolumn{2}{|c|}{ Slight dependence (60-95) } & $57.3 \%$ & $45.3 \%$ & \\
\hline \multicolumn{2}{|c|}{ Moderate dependence (40-55) } & $15.2 \%$ & $32.1 \%$ & \\
\hline \multicolumn{2}{|c|}{ Severe dependence (20-35) } & $7.0 \%$ & $7.5 \%$ & \\
\hline \multicolumn{2}{|c|}{ Complete dependence $(<20)$} & $1.8 \%$ & $3.8 \%$ & \\
\hline \multicolumn{2}{|c|}{ BI Inflection Point (0-55) } & $24.0 \%$ & $43.4 \%$ & 0.002 \\
\hline \multicolumn{2}{|c|}{ Katz Index } & & & 0.033 \\
\hline \multicolumn{2}{|l|}{ A } & $32.7 \%$ & $18.9 \%$ & \\
\hline \multicolumn{2}{|l|}{ B } & $16.2 \%$ & $13.2 \%$ & \\
\hline \multicolumn{2}{|l|}{ C } & $18.7 \%$ & $13.2 \%$ & \\
\hline \multicolumn{2}{|l|}{ D } & $12.5 \%$ & $17.0 \%$ & \\
\hline \multicolumn{2}{|l|}{$\mathrm{E}$} & $7.0 \%$ & $13.2 \%$ & \\
\hline \multicolumn{2}{|l|}{$\mathrm{F}$} & $8.4 \%$ & $18.9 \%$ & \\
\hline \multicolumn{2}{|l|}{ G } & $4.5 \%$ & $5.7 \%$ & \\
\hline \multicolumn{2}{|c|}{ KI Inflection Point (A-B) } & $48.9 \%$ & $32.1 \%$ & 0.017 \\
\hline
\end{tabular}

Abbreviations: $\mathrm{Bl}$, Barthel Index; KI, Katz Index; SD, standard deviation; IQR, interquartile range.

\section{Lawton-Brody Index}

The mean punctuation in the LBI of our population was $3.07 \pm 2.74$. We noted significant increasing LBI punctuations on men, on aging groups, and institutionalized patients at admission ( $\mathrm{p}<0.001$, in all cases), but no differences on LBI were achieved regarding new institutionalized patients at discharge or the early surgery rates $(<24 \mathrm{~h} /$ $48 \mathrm{~h}, \mathrm{p}>0.05$ in all cases).

We showed that LBI distribution was similar in survival and early mortality groups ( $p>0.05$ ), but the single LBI punctuation was significantly related to 30-day mortality (OR per point $=0.885$ [0.788-0.992], $\mathrm{p}=0.037$ ). On the multivariate analysis, we ratify this tendency, but age and gender of patients were adjusting the statistical significance (Supplementary Table 2). Table 3 shows the distributions of LBI punctuation regarding the patients' 30-day mortality status, represented in Figure 2C.

The inflection point previously determined for LBI (LBIIP) was set at 4, distinguishing patients who scored 3 or less and patients who scored 4 or more. Analyzing the study population by the distribution of LBIIP, we observe differences regarding the gender of patients $(p=0.006)$, aging patients $(\mathrm{p}<0.001)$, and the institutionalized population at admission $(\mathrm{p}<0.001)$, but no for new institutionalized patients at discharge $(p>0.05)$. We noted a greater proportion of patients scored 4-8 operated within the first $48 \mathrm{~h}(\mathrm{p}=0.004)$. We noted a tendency for early mortality at this point, but no statistical significance was achieved $\left(\mathrm{OR}_{\mathrm{LBI}(0-3)}=1.801[0.932-3.480], \mathrm{p}=0.080\right)$.

\section{Physical Red Cross Scale}

The mean punctuation in PRCS of our population was 2.0 \pm 0.9 . We noted significant increasing PRCS on aging groups $(\mathrm{p}<0.001)$ and on institutionalized patients at admission $(p<0.001)$, but no differences in PRCS were achieved regarding the gender of patients, among hospitalderived institutionalized patients or time to surgery ( $\mathrm{p}>0.05$, in all cases).

Table 3 shows the distributions of PRCS punctuation regarding the 30-day mortality of patients. We showed that PCRS distribution was similar in survival and early mortality groups (Figure 2D, $>0.05$ ), but the single PRCS punctuation was significantly related to an increased 30-day mortality rate (Figure 1D, OR per point $=1.483$ [1.094-2.011], $\mathrm{p}=0.011$ ), despite the gender or age of patients (Supplementary Table 2).

\section{Discussion}

Our study proposes the use of BI, KI, LBI, and PCRS geriatric scores as standalone indicators of 30-day death probability after hip fracture surgery, validating the established inflection points as key factors for hip fracture patients' management. It all allows us to obtain more detailed knowledge about the prognosis of these patients.

Hip fracture in older patients is indeed a highly demanding health problem. Nowadays, the management of older hip fracture patients has significantly improved thanks to the implementation of the Orthogeriatric Units. ${ }^{13-15}$ It leaded into the CGA which grants a better understanding of the functional and clinical situation of each patient and enables the application of the appropriate therapeutic measures to each case. ${ }^{1,2}$ The functional status geriatric scores applied in the CGA are very useful tools in the assessment of patients admitted to Orthogeriatric Units. ${ }^{6,16}$ The unveiling of the functional status of patients facilitates, inter alia, the comparison of patient's management and care results.

The 30-day mortality may be an indirect indicator of the quality of care and assistance provided to older hip fracture patients. ${ }^{17,18}$ Several studies are trying to find out the risk factors related to a worse outcome. The 


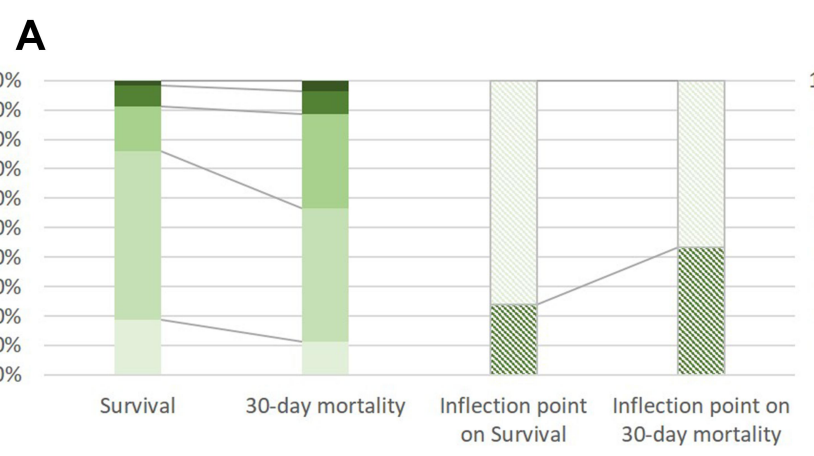

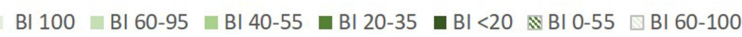

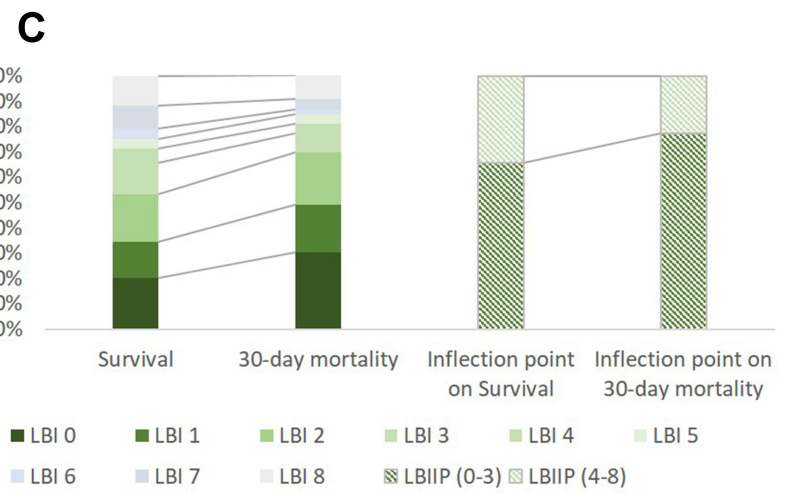

\section{B}

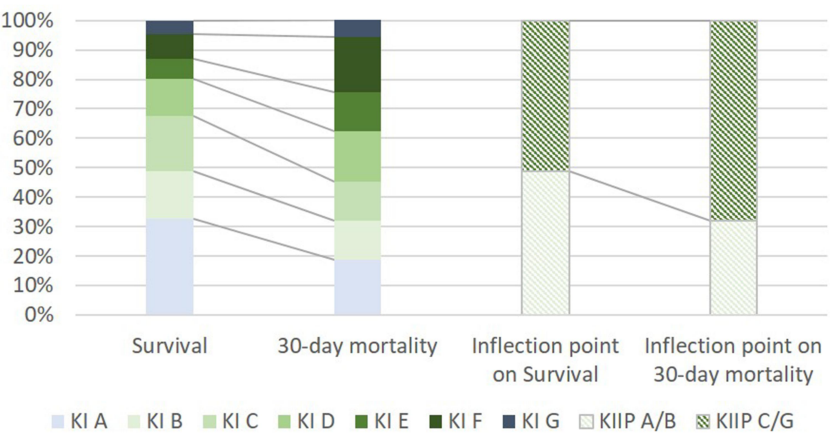

D

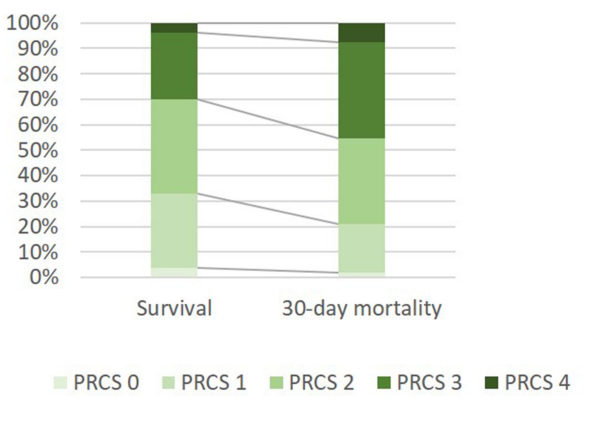

Figure 2 Bar chart of the survival and early mortality population for Barthel Index (A), Katz Index (B), Lawton-Brody Index (C), and Physical Red Cross Scale (D).

recognition of these risk factors would ensure the availability of health care resources for the patients who need them most. Examples of risk factors related to early mortality include non-modifiable factors like age, ${ }^{19}$ gender, ${ }^{20}$ comorbidity, ${ }^{21}$ or even modifiable factors like the waiting time to surgery. ${ }^{22,23}$ Further, different multifactorial models have been proposed for the prediction of 30-day mortality, although due to the complexity of older hip fracture patients, it is very challenging to establish a perfect predictive model. ${ }^{5}$ It would be very useful to have a single multifunctional tool that, in addition to report on the functional status of patients, would allow to advance the prognosis of patients in the short term.

Patient's functional status has been weakly related to the 30-day hip fracture mortality, ${ }^{24}$ although other studies have shown a relationship with in-hospital mortality ${ }^{1,6}$ and long-term mortality. ${ }^{7,25-27}$ The patients' functional status is usually evaluated through the application of geriatric scores that show the ability of patients for personal development in daily life, noting the ADL, IADL, or mobility.

Our population showed a slightly higher mean age and slightly lower 30 -day mortality rate than other previously reported studies on hip fracture populations. ${ }^{28,29}$
We have analyzed the influence of functional status measured through four functional status geriatric scores (BI, KI, LBI, and PRCS) on early mortality. To our knowledge, it is the first time that statistically significant relationships of these four geriatric scores with 30-day mortality is described in detail. The four scores analyzed show good individual discrimination.

We showed significant correlations of each geriatric score analyzed with 30-day mortality, noting that the better the functional status, the better the prognosis. This relationship was expected, although it had never been quantified as it is now. Despite this, no statistically significant association of the geriatric scores analyzed with newly institutionalized patients at discharge emerged. These results point to the use of $\mathrm{BI}, \mathrm{KI}, \mathrm{LBI}$, and PCRS as individual factors influencing the 30-day death probability of older hip fracture patients. We shall not forget the asymmetrical distribution of BI, KI, LBI, and PRCS scores concerning the oldest patients and patients who were institutionalized at admission. Institutionalized and aged patients might be the frailest patients, whose functional status would commit the 30-day death probability.

Since the punctuation of each geriatric score analyzed is continuous data, in order to facilitate clinical and 
Table 3 Lawton-Brody Index and Physical Red Cross Scale Distribution Along the Study Population

\begin{tabular}{|c|c|c|c|c|}
\hline & \multirow{2}{*}{$(n=846)$} & \multirow{2}{*}{$\begin{array}{c}\begin{array}{c}\text { 30-Day } \\
\text { Mortality }\end{array} \\
(n=53)\end{array}$} & \multirow[t]{2}{*}{ p-value } \\
\hline & & & & \\
\hline $\begin{array}{l}\text { Lawton-Brody } \\
\text { Index }\end{array}$ & $\begin{array}{l}\text { Mean } \pm S D \\
\text { Median [IQR] }\end{array}$ & $\begin{array}{c}3.12 \pm 2.7 \\
2[1,5]\end{array}$ & $\begin{array}{c}2.30 \pm 2.6 \\
2[0,3]\end{array}$ & 0.021 \\
\hline \multicolumn{2}{|l|}{0} & $20.1 \%$ & $30.2 \%$ & 0.546 \\
\hline \multicolumn{2}{|l|}{1} & $14.4 \%$ & $18.9 \%$ & \\
\hline \multicolumn{2}{|l|}{2} & $18.9 \%$ & $20.8 \%$ & \\
\hline \multicolumn{2}{|l|}{3} & $12.1 \%$ & $7.5 \%$ & \\
\hline \multicolumn{2}{|l|}{4} & $5.9 \%$ & $3.8 \%$ & \\
\hline \multicolumn{2}{|l|}{5} & $3.8 \%$ & $3.8 \%$ & \\
\hline \multicolumn{2}{|l|}{6} & $4.1 \%$ & $1.9 \%$ & \\
\hline \multicolumn{2}{|l|}{7} & $9.1 \%$ & $3.8 \%$ & \\
\hline \multicolumn{2}{|l|}{8} & $11.6 \%$ & $9.4 \%$ & \\
\hline \multicolumn{2}{|c|}{ LBI Inflection Point (0-3) } & $65.5 \%$ & $77.4 \%$ & 0.076 \\
\hline Physical Red & Mean $\pm S D$ & $1.97 \pm 0.9$ & $2.3 \pm 0.9$ & 0.011 \\
\hline Cross Scale & Median [IQR] & $2[1,3]$ & $2[2,3]$ & \\
\hline \multicolumn{2}{|c|}{ Full ambulatory capability $(0)$} & $3.9 \%$ & $1.9 \%$ & 0.141 \\
\hline \multicolumn{2}{|c|}{ Slight difficulty - no technical aids (I) } & $29.2 \%$ & $18.9 \%$ & \\
\hline \multicolumn{2}{|c|}{ One supporting point (2) } & $37.0 \%$ & $34.0 \%$ & \\
\hline \multicolumn{2}{|c|}{ Two supporting points (3) } & $26.2 \%$ & $37.7 \%$ & \\
\hline \multicolumn{2}{|c|}{ Wheel chair (4) } & $3.7 \%$ & $7.5 \%$ & \\
\hline
\end{tabular}

Abbreviations: LBI, Lawton-Brody Index; SD, standard deviation; IQR, interquartile range.

scientific use, we suggest the use of the inflection points of the geriatric scores to recognize which patients with diverse functional characteristics can benefit from the various levels of care provided. So, we could quantify the increasing risk of early dying regarding the ability to perform ADL before the hip fracture. The BIIP (0-55), or otherwise, the KIIP (A-B), showed the best discriminatory ability to predict the 30-day mortality after hip fracture surgery. These results agree with the previous inflection points validation on $\mathrm{BI}$ and $\mathrm{KI}$ for long-term mortality of hip fracture patients. ${ }^{7}$

Likewise, our study presents some limitations: firstly, the common provenance of the studied population, as it is a single-center study; secondly, the limited use of PRCS, which represents a mobility index that is widely used in Spain but not internationally; lastly, we lack other geriatric tools not applied in our center, as part of a CGA addressed in other studies (like geriatric comorbidity index).

\section{Conclusions}

The geriatric scores analyzed (BI, KI, LBI and PCRS) are single-handedly related in a statistically significant way to the 30-day mortality after hip fracture surgery. We show key inflection points for $\mathrm{BI}$ and $\mathrm{KI}$ on $\mathrm{ADL}$ that individually could assess the raising 30-day mortality risk after hip fracture surgery.

In our belief, the four geriatric scores here presented, in addition to inform about the functional status of patients, could provide risk assessment for the 30-day mortality of hip fracture patients.

\section{Abbreviations}

ADL, Activities of daily living; BI, Barthel index; CI, Confidence interval; CGA, Comprehensive geriatric assessment; FAC, Functional Ambulation Classification; IADL, Instrumental activities of daily living; IP, Inflection point; KI, Katz index; LBI, Lawton-Brody index; OR, Odds ratio; PCRS, Physical Red Cross Scale; UHS, University Hospital of Salamanca.

\section{Data Sharing Statement}

The data supporting this study are available from the corresponding author upon reasonable request.

\section{Ethics Approval and Consent to Participate}

All participants (or their relatives) have given their written informed consent to participate. The whole study was conducted following the Declaration of Helsinki and was previously approved by the ethics committee for clinical research (CEIm) of the University Hospital of Salamanca.

\section{Consent for Publication}

Not applicable.

\section{Author Contributions}

All authors made substantial contributions to conception and design, acquisition of data, or analysis and interpretation of data; took part in drafting the article or revising it critically for important intellectual content; agreed to submit to the current journal; gave final approval of the version to be published; and agree to be accountable for all aspects of the work.

\section{Funding}

No specific funding for this study and its publication was obtained. 


\section{Disclosure}

The authors have no conflicts of interest to declare for this work.

\section{References}

1. Avelino-silva TJ, Farfel JM, Curiati JAE, Amaral JRG, Campora F, Jacob-filho W. Comprehensive geriatric assessment predicts mortality and adverse outcomes in hospitalized older adults. BMC Geriatr. 2014;14:129. doi:10.1186/1471-2318-14-129

2. Parker SG, McCue P, Phelps K, et al. What is Comprehensive Geriatric Assessment (CGA)? An umbrella review. Ruggiero C ed. Age Ageing. 2018;47(1):149-155. doi:10.1093/ageing/afx166

3. Desforges JF, Applegate WB, Blass JP, Williams TF. Instruments for the Functional Assessment of Older Patients. $N$ Engl J Med. 1990;322(17):1207-1214. doi:10.1056/NEJM199004263221707

4. Marufu TC, Mannings A, Moppett IK. Risk scoring models for predicting peri-operative morbidity and mortality in people with fragility hip fractures: qualitative systematic review. Injury. 2015;46 (12):2325-2334. doi:10.1016/j.injury.2015.10.025

5. Karres J, Heesakkers NA, Ultee JM, Vrouenraets BC. Predicting 30-day mortality following hip fracture surgery: evaluation of six risk prediction models. Injury. 2015;46(2):371-377. doi:10.1016/j. injury.2014.11.004

6. Kim K, Park K-H, Koo K-H, Han H-S, Kim C-H. Comprehensive geriatric assessment can predict postoperative morbidity and mortality in elderly patients undergoing elective surgery. Arch Gerontol Geriatr. 2013;56(3):507-512. doi:10.1016/j.archger.2012.09.002

7. da Casa C, Pablos-Hernández C, González-Ramírez A, Julián-Enriquez JM, Blanco JF. Geriatric scores can predict long-term survival rate after hip fracture surgery. BMC Geriatr. 2019;19(1):205. doi:10.1186/s12877-019-1223-y

8. Mahoney FI, Barthel DW. Functional evaluation: the Barthel Index. Md State Med J. 1965;14:61-65.

9. Katz SM, Ford AB, Moskowitz RW, Jackson BA, Jaffe MW. Studies of illness in the aged: the index of ADL. A standardized measure of biological and psychosocial function. JAMA J Am Med Assoc. 1963;185(12):914-919. doi:10.1001/jama.1963.03060120024016

10. Lawton MP, Brody EM. Assessment of older people: self-maintaining and instrumental activities of daily living. Gerontologist. 1969;9 (3):179-186. doi:10.1093/geront/9.3_Part_1.179

11. Vergara I, Bilbao A, Orive M, Garcia-Gutierrez S, Navarro G, Quintana J. Validation of the Spanish version of the Lawton IADL Scale for its application in elderly people. Health Qual Life Outcomes. 2012;10(1):130. doi:10.1186/1477-7525-10-130

12. Guillén LLera F, García Antón A. Ayuda a domicilio. Aspectos médicos en geriatría. Rev Española Gerontol. 1972;7:339-346.

13. Grigoryan KV, Javedan H, Rudolph JL. Orthogeriatric care models and outcomes in hip fracture patients. J Orthop Trauma. 2014;28(3): e49-e55. doi:10.1097/BOT.0b013e3182a5a045

14. Kristensen PK, Thillemann TM, Søballe K, Johnsen SP. Can improved quality of care explain the success of orthogeriatric units? A population-based cohort study. Age Ageing. 2016;45(1):66-71. doi:10.1093/ageing/afv155
15. Pablos-Hernández C, González-Ramírez A, da Casa C, et al. Time to surgery reduction in hip fracture patients on an integrated orthogeriatric unit: a comparative study of three healthcare models. Orthop Surg. 2020;12(2):457-462. doi:10.1111/os.12633

16. Mayoral AP, Ibarz E, Gracia L, Mateo J, Herrera A. The use of Barthel index for the assessment of the functional recovery after osteoporotic hip fracture: one year follow-up. PLoS One. 2019;14 (2):e0212000. doi:10.1371/journal.pone.0212000

17. Pincus D, Ravi B, Wasserstein D, et al. Association between wait time and 30-day mortality in adults undergoing hip fracture surgery. JAMA. 2017;318(20):1994. doi:10.1001/jama.2017.17606

18. Voeten SC, Krijnen P, Voeten DM, Hegeman JH, Wouters MWJM, Schipper IB. Quality indicators for hip fracture care, a systematic review. Osteoporos Int. 2018;29(9):1963-1985. doi:10.1007/s00198018-4558-x

19. Forni C, Gazineo D, D'Alessandro F, et al. Predictive factors for thirty day mortality in geriatric patients with hip fractures: a prospective study. Int Orthop. 2019;43(2):275-281. doi:10.1007/s00264-018-4057-x

20. Kannegaard PN, van der Mark S, Eiken P, Abrahamsen B. Excess mortality in men compared with women following a hip fracture. National analysis of comedications, comorbidity and survival. Age Ageing. 2010;39(2):203-209. doi:10.1093/ageing/afp221

21. Sheikh HQ, Hossain FS, Aqil A, Akinbamijo B, Mushtaq V, Kapoor H. A comprehensive analysis of the causes and predictors of 30-day mortality following hip fracture surgery. Clin Orthop Surg. 2017;9(1):10-18. doi:10.4055/cios.2017.9.1.10

22. Moja L, Piatti A, Pecoraro V, et al. Timing matters in hip fracture surgery: patients operated within 48 hours have better outcomes. a meta-analysis and meta-regression of over 190,000 patients. PLoS One. 2012;7(10):e46175. doi:10.1371/journal.pone.0046175

23. Nyholm AM, Gromov K, Palm H, et al. Time to surgery is associated with thirty-day and ninety-day mortality after proximal femoral fracture. $J$ Bone Jt Surg Am Vol. 2015;97(16):1333-1339. doi:10.2106/JBJS.O.00029

24. Parada Freitas Y, Fernández Arana L, Garay Airaghi V, Lueje Alonso E, Mora Fernández J. Mortalidad temprana y tardía en el paciente anciano con fractura de cadera. Rev Esp Geriatr Gerontol. 2018;53:40-41. doi:10.1016/j.regg.2018.04.099

25. Martínez-Velilla N, Ibáñez-Beroiz B, Cambra-Contin K, Alonso-Renedo $\mathrm{J}$. Is comprehensive geriatric assessment a better 1-year mortality predictor than comorbidity and prognostic indices in hospitalized older adults? $\mathrm{J} \mathrm{Am}$ Geriatr Soc. 2013;61(10):1821-1823. doi:10.1111/jgs.12488

26. Martínez-Velilla N, Cambra-Contin K, Ibáñez-Beroiz B. Comorbidity and prognostic indices do not improve the 5 -year mortality prediction of components of comprehensive geriatric assessment in hospitalized older patients. BMC Geriatr. 2014;14(1):64. doi:10.1186/1471-2318-14-64

27. Kristensen MT, Kehlet $H$. The basic mobility status upon acute hospital discharge is an independent risk factor for mortality up to 5 years after hip fracture surgery Survival rates of 444 pre-fracture ambulatory patients evaluated with the Cumulated Ambulation Score. Acta Orthop. 2018;89(1):47-52. doi:10.1080/17453674.2017.1382038

28. Giannoulis D, Calori GM, Giannoudis PV. Thirty-day mortality after hip fractures: has anything changed? Eur J Orthop Surg Traumatol. 2016;26(4):365-370. doi:10.1007/s00590-016-1744-4

29. Ojeda-Thies C, Sáez-López P, Currie CT, et al. Spanish National Hip Fracture Registry (RNFC): analysis of its first annual report and international comparison with other established registries. Osteoporos Int. 2019;30(6):1243-1254. doi:10.1007/s00198-019-04939-2 


\section{Publish your work in this journal}

Clinical Interventions in Aging is an international, peer-reviewed journal focusing on evidence-based reports on the value or lack thereof of treatments intended to prevent or delay the onset of maladaptive correlates of aging in human beings. This journal is indexed on PubMed Central, MedLine, CAS, Scopus and the Elsevier
Bibliographic databases. The manuscript management system is completely online and includes a very quick and fair peer-review system, which is all easy to use. Visit http://www.dovepress.com/ testimonials.php to read real quotes from published authors.

Submit your manuscript here: https://www.dovepress.com/clinical-interventions-in-aging-journal 